\title{
Prehospitalt forløp ved akutt hjerneslag
}

BAKGRUNN Pasienter med akutt hjerneslag behandles ikke ofte nok med trombolyse på grunn av et begrenset tidsvindu og prehospital forsinkelse. Hensikten med denne studien er å beskrive det prehospitale forløpet for disse pasientene, og spesielt hva som skiller pasientene som kontakter akuttmedisinsk kommunikasjonssentral (AMK) sammenlignet med pasienter som kontakter fastlege og legevakt.

MATERIALE OG METODE Pasienter med akutt hjerneinfarkt og intracerebral blødning innlagt ved Seksjon for akutt hjerneslag, Nevroklinikken, Akershus universitetssykehus, ble inkludert. Data for det prehospitale forløpet (prehospital forsinkelse, medisinske kontakter) ble innsamlet i perioden 15.4.2009-1.4.2010.

RESULTATER Totalt 299 pasienter ble inkludert i studien, med median alder 75 år, hvorav $48,5 \%$ var kvinner. Til sammen kontaktet $63,9 \%$ av pasientene med akutt hjerneslag AMKsentralen, og 93,7\% av disse ble transportert direkte til sykehus i ambulanse. Av de pasientene som kontaktet fastlegekontor/legevakt per telefon, ble 60,7\% bedt om å møte opp på fastlegekontor/legevakt. Pasientene som kontaktet og møtte opp på fastlegekontor/legevakt først, hadde mildere nevrologiske utfall $(p<0,001)$ og lengre pasientforsinkelse $(p=0,018)$ enn pasientene som kontaktet AMK-sentral.

FORTOLKNING Seks av ti pasienter som kontaktet primærhelsetjenesten ble bedt om å møte opp på fastlegekontor/legevakt, noe som medførte unødvendig tidstap. Funnene fra studien kan bety at det bør fokuseres på spesifikk opplæring i raskere håndtering av pasienter med mulige hjerneslag for denne helsepersonellgruppen.

Hjerneslag er en av de vanligste årsakene til død og den vanligste årsaken til alvorlig funksjonshemning (1). Omtrent 15000 mennesker rammes av hjerneslag hvert år (1). Flesteparten av pasientene er eldre, og på grunn av økning $i$ antall eldre er det forventet at antall hjerneslag vil øke i fremtiden (2).

Det er beregnet at omtrent to millioner nevroner skades per minutt ved et stort, ubehandlet hjerneinfarkt (3). Behandling med intravenøs trombolyse ved hjerneinfarkt er begrenset av et tidsvindu for behandlingsstart oppad til 4,5 timer etter symptomdebut, og effekten av slik behandling avtar gradvis innenfor dette tidsvinduet (4-6). Dør-tilnål-tid på maksimalt 40 minutter er en nasjonal kvalitetsindikator (7), og ved mange sykehus er det etablert egne logaritmer og rutiner for pasienter som innlegges som «trombolysekandidater». Likevel behandles et fåtall av pasientene med intravenøs trombolyse, primært på grunn av prehospital forsinkelse (8-10). I $2015 \mathrm{kom}$ det flere studier som viste positiv effekt av trombektomi, men også denne behandlingen må gis innenfor et begrenset tidsvindu på seks timer (11)

Alle pasienter med akutt hjerneslag bør innlegges akutt på sykehus. Ved mistanke om akutt hjerneslag bør det umiddelbart tas kontakt med akuttmedisinsk kommunikasjonssentral (AMK) for raskest mulig innleggelse og vurdering for trombolyse/trombektomi. Mange pasienter tar ikke direkte kontakt med AMK-sentralen, og det kan dermed oppstå forsinkelser til trombolytisk be- handling. Hvis en pasient med akutt hjerneslag kontakter fastlege/legevakt, bør denne medvirke til rask innleggelse.

Hensikten med denne studien var å beskrive det prehospitale forløpet for pasienter med akutt hjerneslag, inkludert tidsbruk, og forskjeller mellom pasienter som kontakter AMK-sentral sammenlignet med pasienter som kontakter primærhelsetjenesten (fastlege/legevakt), og å studere hvordan helsepersonell ved AMK-sentralene og i primærhelsetjenesten responderte på varsel om pasient med symptomer på hjerneslag.

\section{Materiale og metode}

Denne prospektive observasjonsstudien var en del av et større prosjekt om prehospital forsinkelse ved og kunnskap om hjerneslag, gjennomført i perioden 15.4. 2009-1.4. 2010 ved Seksjon for akutt hjerneslag, Nevroklinikken, Akershus universitetssykehus. Alle pasienter i opptaksområdet (til sammen omtrent 360000 personer 1.1. 2010) med spørsmål om hjerneslag ble innlagt ved Nevroklinikken, uavhengig av alder.

Alle pasienter med hjerneinfarkt og intracerebral blødning som utskrivelsesdiagnose ble inkludert i studien $(\mathrm{n}=440)$, da det før innleggelse og avklaring med CT caput ikke er mulig å differensiere tilstandene. Pasienter med hjerneslagimitatorer (andre endelige diagnoser), forbigående symptomer (endelig diagnose transitorisk iskemisk anfall) eller over ett døgns symptomvarighet før innleggelse ble ekskludert. Pasienter som møtte

\section{Kashif Waqar Faiz}

kashif.faiz@medisin.uio.no Nevroklinikken

Akershus universitetssykehus og

Helsetjenesteforskning

Akershus universitetssykehus

Antje Sundseth

Bente Thommessen

Nevroklinikken

Akershus universitetssykehus

Ole Morten Rønning

Nevroklinikken

Akershus universitetssykehus

og

Institutt for klinisk medisin

Det medisinske fakultet

Universitetet i Oslo

> Se lederartikkel side 778

TL

Engelsk oversettelse på www.tidsskriftet.no

\section{HOVEDBUDSKAP}

To av tre pasienter med akutt hjerneslag kontaktet akuttmedisinsk kommunikasjonssentral som første medisinske kontakt, og over $90 \%$ av disse ble transportert i ambulanse direkte til sykehus

Mer enn $60 \%$ av de pasientene som kontaktet fastlegekontor eller legevakt, ble bedt om å møte opp på fastlegekontor/ legevakt

Pasienter som kontaktet og møtte opp på fastlegekontor/legevakt først, hadde mildere utfall og lengre pasientforsinkelse enn pasientene som kontaktet akuttmedisinsk kommunikasjonssentral, og signifikant færre fikk intravenøs trombolyse 
direkte i akuttmottaket uten kontakt med helsetjenesten på forhånd, og pasienter som fikk hjerneslag under sykehusoppholdet, ble også ekskludert. Figur 1 viser studieinklusjon og eksklusjon.

Alle pasienter og/eller pårørende ble intervjuet innen 72 timer etter innleggelse, og et strukturert spørreskjema ble fylt ut. I tillegg ble elektronisk pasientjournal gjennomgått slik at relevante data kunne registreres.

Pasientforsinkelse ble definert som tiden fra symptomdebut til første kontakt med helsetjenesten. Prehospital forsinkelse ble definert som tiden fra symptomdebut til ankomst akuttmottak. Kontakt med helsetjenesten inkluderte telefonisk kontakt med AMK-sentralen, telefonisk kontakt med fastlegekontor/legevakt og oppmøte på fastlegekontor/legevakt. Informasjon om tidligere hjerneslag og hjertesykdom ble innhentet fra elektronisk journalsystem. Nevrologiske utfall ble kvantifisert ved bruk av den norske versjonen av National Institutes of Health Stroke Scale (NIHSS) (skår 0 = ingen symptomer, maksimalskår 42) (12).

\section{Statistikk}

Kontinuerlige data presenteres som medianverdier med nedre og øvre kvartil da de ikke var normalfordelte. Sammenligning mellom gruppene ble gjort med Mann-Whitney U-test. Kategoriske data er oppgitt i abso-

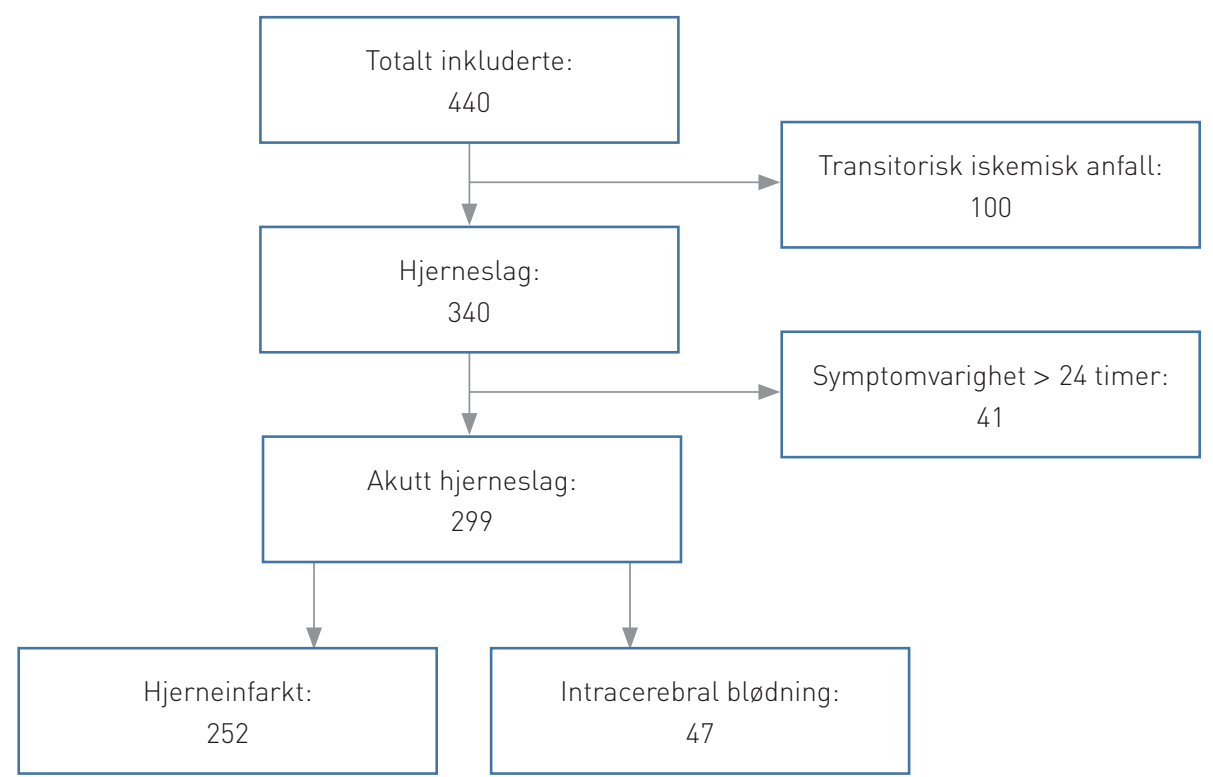

Figur 1 Totalt ble alle pasienter med hjerneinfarkt og intracerebral blødning inkludert i studien ( $n=440)$. Pasienter med forbigående symptomer eller over ett døgns symptomvarighet før innleggelse ble ekskludert ( $n=141)$

lutte tall og prosentverdier, og gruppene ble sammenlignet med Pearson/Fishers eksakte khikvadrattest. P-verdi $<0,05$ ble vurdert som statistisk signifikant. Statistiske analyser ble utført med SPSS versjon 22 (IBM SPSS, Chicago, IL, USA).

\section{Etikk}

Prosjektet ble vurdert av Regional etisk komité, som konkluderte med at det ikke var fremleggingspliktig. Prosjektet er godkjent av lokalt personvernombud.

Tabell 1 Oversikt over pasienter inndelt etter hva som var første medisinske kontakt - enten akuttmedisinsk kommunikasjonssentral (AMK) eller fastlegekontor/legevakt. Alle pasienter var innlagt i Nevroklinikken, Akershus universitetssykehus, med akutt hjerneslag i perioden 15.4. 2009-1.4. 2010

\begin{tabular}{|c|c|c|c|c|}
\hline & Alle & AMK-sentral & $\begin{array}{l}\text { Fastlegekontor/ } \\
\text { legevakt }\end{array}$ & P-verdi \\
\hline Antall (\%) & 299 (100) & $191(63,9)$ & $108(36,1)$ & \\
\hline Alder, år, median (nedre og øvre kvartil) & $75(65-82)$ & $76(67-82)$ & $73(64-82)$ & 0,308 \\
\hline Kvinner (\%) & $145(48,5)$ & $90(47,1)$ & $55(50,9)$ & 0,527 \\
\hline Aleneboende (\%) & $133(44,5)$ & $82(42,9)$ & $51(47,2)$ & 0,691 \\
\hline Tidligere hjerneslag (\%) & $93(31,1)$ & $66(34,6)$ & $27(25,0)$ & 0,086 \\
\hline Tidligere hjertesykdom (\%) & $110(36,8)$ & $77(40,3)$ & $33(30,6)$ & 0,093 \\
\hline $\begin{array}{l}\text { National Institutes of Health Stroke Scale (NIHSS)-skår' median } \\
\text { (nedre og øvre kvartil) }\end{array}$ & $5(2-12)$ & $7(3-17)$ & $3(1-5)$ & 0,001 \\
\hline Ankomst med ambulanse (\%) & $247(82,6)$ & $187(97,9)$ & $60(55,6)$ & $<0,001$ \\
\hline Pasientforsinkelse, minutter, median (nedre og øvre kvartil) & $66(18-210)$ & $35(10-120)$ & $172(66-383)$ & $<0,001$ \\
\hline Transportforsinkelse, minutter, median (nedre og øvre kvartil) & $57(40-89)$ & $46(34-60)$ & $115(66-226)$ & 0,023 \\
\hline Prehospital forsinkelse, minutter, median (nedre og øvre kvartil) & $140(69-362)$ & $83(59-164)$ & $352(188-636)$ & 0,018 \\
\hline Hjerneinfarkt (\%) & $252(84,3)$ & $156(81,7)$ & $96(88,9)$ & 0,100 \\
\hline Intravenøs trombolyse, antall/antall hjerneinfarkt (\%) & $22 / 252(8,7)$ & $20 / 156(12,8)$ & $2 / 96(2,1)$ & 0,003 \\
\hline
\end{tabular}




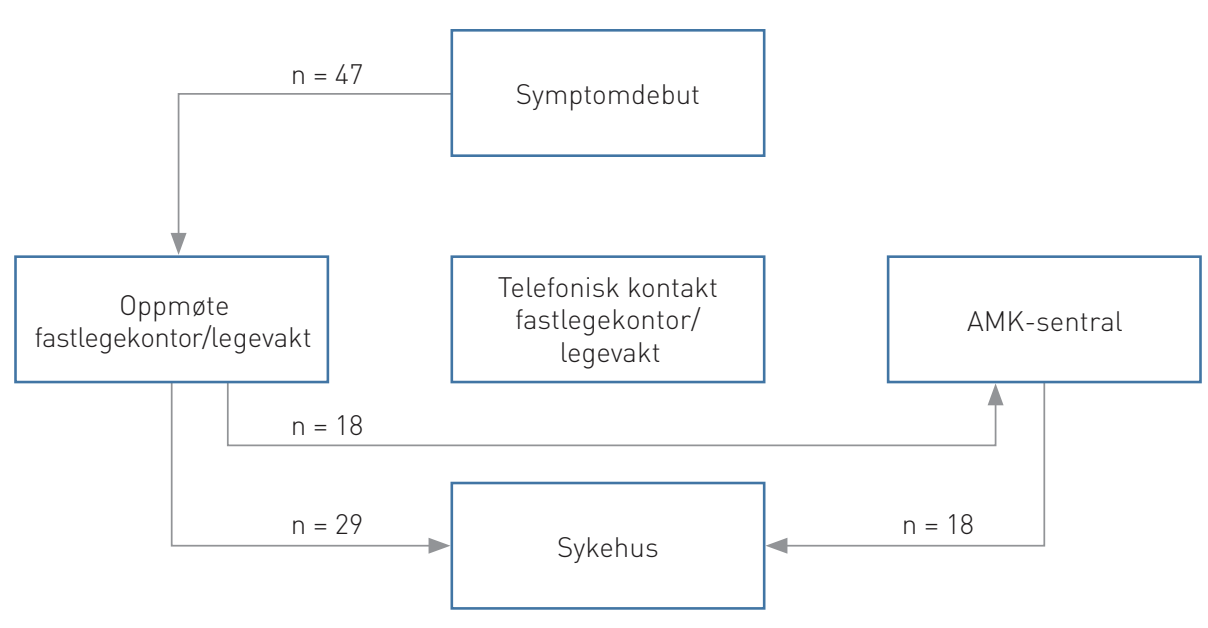

a

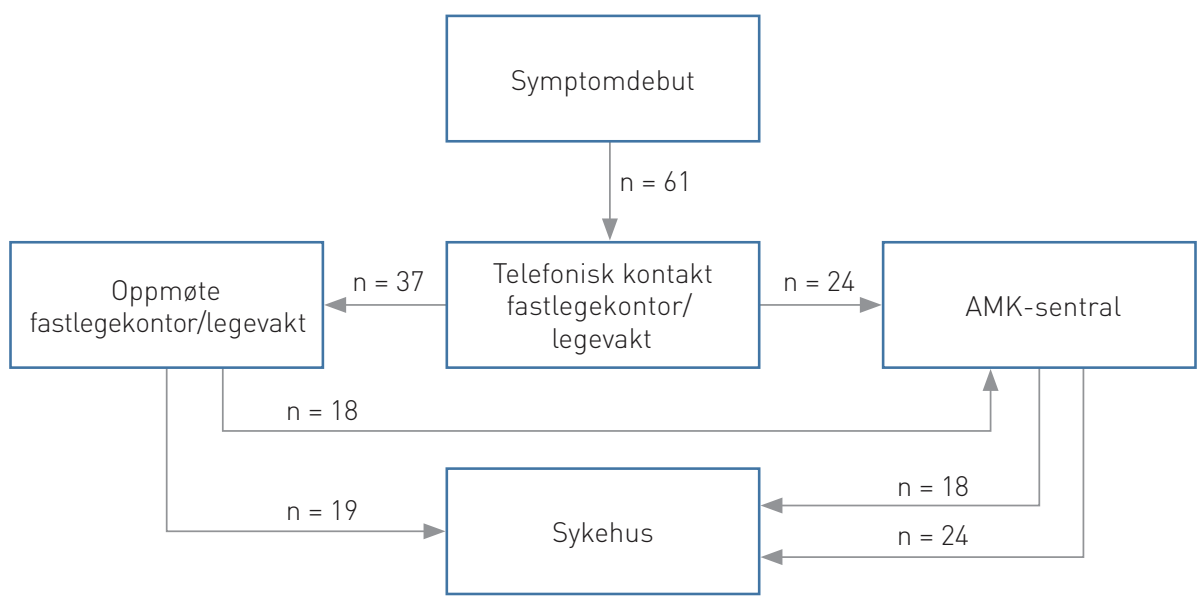

b

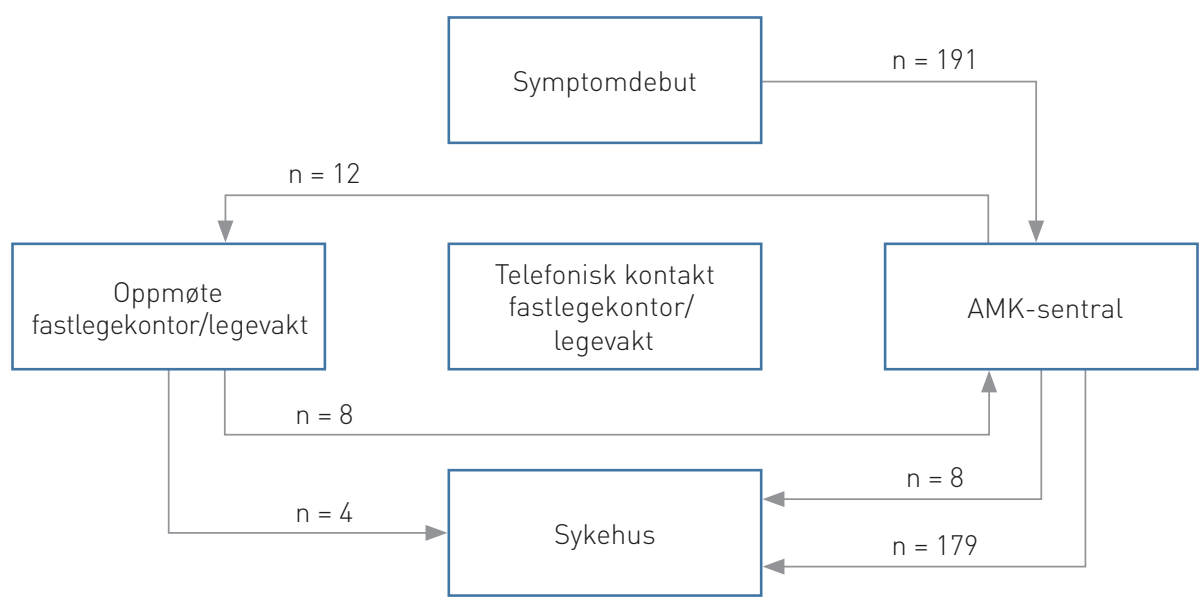

Figur 2 Prehospitalt forløp ved akutt hjerneslag for pasienter inndelt etter hva som var første medisinske kontakt - enten akuttmedisinsk kommunikasjonssentral (AMK) eller fastlege/legevakt. Alle pasienter var innlagt i Nevroklinikken, Akershus universitetssykehus, med akutt hjerneslag i perioden 15.4. 2009-1.4. 2010. al Første medisinske kontakt: oppmøte på fastlegekontor/legevakt, b) Første medisinske kontakt: telefonisk kontakt med fastlegekontor/legevakt, c) Første medisinske kontakt: telefonisk kontakt med AMK-sentral

\section{Resultater}

Totalt 299 pasienter ble inkludert i studien, hvorav 252 med hjerneinfarkt og 47 med intracerebral blødning. Median alder var 75 år (65-82), og 145 (48,5\%) var kvinner. Til sammen $191(63,9 \%)$ pasienter tok telefonisk kontakt med AMK-sentral som første kontakt med helsetjenesten, mens $61(20,4 \%)$ pasienter tok telefonisk kontakt med fastlegekontor/legevakt (henholdsvis 36/25), og 47 $(15,7 \%)$ pasienter møtte direkte opp på fastlegekontor/legevakt (henholdsvis 14/33) uten forutgående telefonisk kontakt.

Av de 191 pasientene som kontaktet AMK-sentral, ble $179(93,7 \%)$ kjørt direkte til sykehus i ambulanse, mens $12(6,3 \%)$ ble bedt om å oppsøke eller ble transportert til fastlegekontor/legevakt. Av disse 12 pasientene ble åtte innlagt med ambulanse.

Av de 61 pasientene som tok telefonisk kontakt med fastlegekontor/legevakt, ble 37 $(60,7 \%)$ bedt om å møte opp på fastlegekontoret/legevakten for legevurdering, mens 24 $(39,3 \%)$ ble satt over til AMK-sentralen. Av de 37 pasientene som ble bedt om å møte opp på fastlegekontor/legevakt, ble 18 innlagt via AMK-sentralen, mens 19 ble innlagt via annen transportmåte, uten involvering av AMK-sentral.

Av de til sammen 96 pasientene som ble vurdert av fastlege/legevaktslege (oppmøte, både som første- og andrekontakt), ble 44 $(45,8 \%)$ innlagt med ambulanse, mens resterende $(54,2 \%)$ reiste til sykehus med annen transport. Det prehospitale forløpet er vist i detalj i figur 2.

I tabell 1 oppsummerer vi funn for alle pasienter samlet og inndelt etter AMK-sentral eller fastlegekontor/legevakt som første medisinske kontakt. Pasientene som kontaktet eller møtte opp hos fastlege eller legevakt, hadde signifikant lavere NIHSS-skår $(p=0,001)$, signifikant lengre pasientforsinkelse $(<0,001)$ og prehospital forsinkelse $(p=0,018)$ og signifikant lavere trombolysefrekvens $(\mathrm{p}=0,003)$. Det var ingen signifikante forskjeller mellom gruppene for alder, kjønnsfordeling, andel med tidligere hjertesykdom og andel med tidligere hjerneslag.

\section{Diskusjon}

Denne studien viste at av totalt 299 pasienter med akutt hjerneslag kontaktet $63,9 \%$ av pasientene AMK-sentral som første kontakt med helsetjenesten, hvorav $93,7 \%$ ble transportert direkte til sykehus i ambulanse. Av de pasientene som kontaktet fastlegekontor eller legevakt per telefon, ble $60,7 \%$ bedt om å møte opp på fastlegekontoret eller legevakten. Av de pasientene som ble vurdert av fastlege eller legevaktslege, ble 45,8 \% transportert til sykehus i ambulanse. Pasientene som kontaktet primærhelsetjenesten som første medisinske kontakt (telefonisk kontakt eller 
oppmøte på fastlegekontor/legevakt), hadde mildere utfall og lengre pasientforsinkelse enn pasientene som kontaktet AMK-sentralen. Omtrent halvparten av pasientene som etter telefonisk kontakt med fastlegekontor/ legevakt ble bedt om å møte opp på fastlegekontoret/legevakten, ble innlagt uten involvering av AMK-sentralen.

Trombolysefrekvens ved hjerneinfarkt er en nasjonal kvalitetsindikator, og for andre tertial 2015 var landsgjennomsnittet 14,6\% (13). Indikatoren inkluderer kun pasienter opptil 80 år. Av ti nye nasjonale kvalitetsindikatorer som ble offentliggjort av Helsedirektoratet i februar 2016, omhandlet tre av disse hjerneinfarkt (14).

Til tross for innleggelse innenfor tidsvindu finnes absolutte og relative kontraindikasjoner mot intravenøs trombolyse, og behandlingen blir gitt etter en helhetlig vurdering. Likevel viser flere studier at prehospital forsinkelse er den vanligste årsaken til lav trombolysefrekvens, det vil si at mange av pasientene kommer for sent til sykehuset til å kunne vurderes for intravenøs trombolyse (15-17). I den forbindelse har man konsentrert seg om informasjonskampanjer om hjerneslag rettet mot den generelle befolkningen og mot spesielle befolkningsgrupper (18-20). Studier viser at slike kampanjer har god, men kortvarig effekt, og at økt kunnskap om hjerneslag ikke nødvendigvis fører til endret atferd/handling på sikt (21). Akronymet FAST (Face, Arm, Speech, Time) er blitt brukt i flere engelsktalende land. I Norge er ulike akronymer blitt brukt (22), og det er foreslått landsomfattende opplysningskampanjer, med eller uten akronymer. I en nylig publisert norsk studie ble effekten av en informasjonskampanje om hjerneslag på Vestlandet evaluert. I studien konkluderte man med god effekt i seks måneder med tanke på trombolysefrekvens og antall innleggelser med spørsmål om hjerneslag, men med avtagende effekt senere i forløpet (23).

I denne studien ble ni av ti pasienter som kontaktet AMK-sentralen transportert direkte til sykehus i ambulanse, mens kun fire av ti pasienter som kontaktet primærhelsetjenesten ble overført til AMK-sentralen og direkte sykehusinnleggelse. «Omveien» om fastlegekontor eller legevakt medfører unødvendig tidstap og høy risiko for at pasienten ikke kan vurderes for intravenøs trombolyse eller trombektomi innenfor et begrenset tidsvindu. Pasientene som tok telefonisk kontakt eller møtte opp på fastlegekontor/legevakt hadde lavere NIHSS-skår enn pasientene som kontaktet AMK-sentralen, men milde utfall er ingen kontraindikasjon mot intravenøs trombolyse $(6,24)$, og utfallene kan forverres senere i forløpet. På den andre siden ble ikke type symptomer registrert i denne studien, og det kan antas at en høyere andel av disse pasientene hadde atypiske symptomer slik at andre diagnoser enn hjerneslag ble vurdert som mer sannsynlige, og dermed den initiale vurderingen via fastlegekontor/ legevakt. I tillegg hadde pasientene lengre pasientforsinkelse enn pasientene som kontaktet AMK-sentralen, slik at flere av disse uansett ikke kunne ha blitt vurdert for intravenøs trombolyse eller trombektomi.

Hjerneslagsymptomer er på mange måter mer utfordrende enn for eksempel koronarsuspekte symptomer, både på grunn av variasjon i symptombilde og grad av symptomer, men også på grunn av mulighet for kognitive utfall og kommunikasjonsproblemer (afasi, dysartri) eller manglende forståelse av egen situasjon. Over $60 \%$ av pasientene som kontaktet fastlegekontor eller legevakt ble bedt om å møte opp på fastlegekontoret eller legevakten, noe som medførte unødvendig tidstap. Et mulig tiltak for å redusere dette tidstapet kan være å fokusere på økt opplæring/ undervisning om hjerneslag for helsepersonell som møter pasienter med mulig hjerneslag i akuttfasen som forste medisinske kontakt, noe som også er blitt foreslått av Akuttutvalget $(25,26)$. Slik undervisning bør rettes spesielt mot de som besvarer telefonsamtaler på fastlegekontorer og legevakter, vanligvis helsesekretærer, sykepleiere eller medisinstudenter. I tillegg er det behov for informasjonskampanjer om hjerneslag i befolkningen, da pårørende ofte er de første som møter pasienten. Informasjonen kan gis som for eksempel undervisning på skolen, på venteværelser på legekontorer, eller som reklamekampanjer på tv og internett, i tidsskrifter og aviser og eventuelt på melkekartonger.

Vi har ikke undersøkt kunnskap blant helsepersonell som møter pasienter med hjerneslag i akuttfasen, det vil si de som besvarer den første telefonen fra en pasient med akutt hjerneslag. En måte å kartlegge helsepersonellets kunnskap og håndtering av akutt hjerneslag er ved bruk av fiktive pasientkasuistikker. I en studie fra Storbritannia (27) ble legekontorer uanmeldt ringt til og presentert for fiktive pasientkasuistikker (gradert enkle, moderat vanskelige eller vanskelige), og responsen ble registrert. Kasuistikker med mange symptomer ble i studien gjenkjent som mulig hjerneslag og henvist til AMK-sentralen, mens færre og atypiske symptomer ga ikke slik respons. I en studie fra USA (28) ble telefonoperatører ved ulike sykehus presentert for et standardisert hjerneslagscenario, og de ble bedt om å velge én av fire ulike responser, i tillegg til å benevne de vanligste symptomene ved hjerneslag. Totalt $22 \%$ anbefalte at pasienten tok kontakt med fastlege.

Studien har flere svakheter. Hjerneslagimitatorer ble ikke inkludert, slik at sensi- tivitet og spesifisitet ikke kunne beregnes. Hvem som tok kontakt med helsetjenesten (pasient eller pårørende), ble heller ikke registrert. Studien ble gjennomført i perioden 2009-10, det vil si før publisering av Nasjonal faglig retningslinje for behandling og rehabilitering ved hjerneslag (1). I tillegg er behandling av hjerneslag et av innsatsområdene i det nasjonale pasientsikkerhetsprogrammet I trygge hender (29), slik at det vil være rimelig å anta at situasjonen kan være endret med økt søkelys på raskere innleggelse for pasienter med hjerneslag. Vi mener likevel at mange av funnene er relevante fremdeles.

\section{Konklusjon}

Over $90 \%$ av pasientene med akutt hjerneslag som tok kontakt med AMK-sentraler som første medisinske kontakt, ble transportert direkte til sykehus, mens over $60 \%$ av pasientene som kontaktet fastlegekontor eller legevakt, ble bedt om å møte opp på fastlegekontoret eller legevakten, noe som medfører unødvendig tidstap. Man bør fokusere på kunnskap om hjerneslag både $\mathrm{i}$ befolkningen og blant helsepersonell.

Manuskriptet til denne artikkelen ble sendt inn før oppstart av den nasjonale hjerneslagkampanjen (28.10. 2016), og kampanjen er derfor ikke omtalt i diskusjonsdelen.

\section{Kashif Waqar Faiz (f. 1978)}

er spesialist i nevrologi, ph.d., master i helseadministrasjon og seksjonsleder/overlege og forsker ved henholdsvis Nevroklinikken og Helsetjenesteforskning, Akershus universitetssykehus.

Forfatter har fylt ut ICMJE-skjemaet og oppgir ingen interessekonflikter.

\section{Antje Sundseth (f. 1975)}

er spesialist i nevrologi, ph.d. og overlege ved Nevroklinikken, Akershus universitetssykehus. Forfatter har fylt ut ICMJE-skjemaet og oppgir ingen interessekonflikter.

\section{Bente Thommessen (f. 1954)}

er spesialist i nevrologi, dr.med. og seksjonsleder/overlege ved Nevroklinikken, Akershus universitetssykehus

Forfatter har fylt ut ICMJE-skjemaet og oppgir ingen interessekonflikter.

\section{Ole Morten Rønning (f. 1961)}

er spesialist i nevrologi, dr.med., seksjonsleder/ overlege ved Nevroklinikken, Akershus universitetssykehus, og førsteamanuensis, Institutt for klinisk medisin, Universitetet i Oslo. Forfatter har fylt ut ICMJE-skjemaet og oppgir ingen interessekonflikter. 


\section{Litteratur}

1. Nasjonal retningslinje for behandling og rehabilitering ved hjerneslag. Oslo: Helsedirektoratet 2010

2. Scenario 2030 - Sykdomsutviklingen for eldre fram til 2030. Oslo: Statens helsetilsyn, 1999.

3. Saver JL. Time is brain-quantified. Stroke 2006; 37: 263-6.

4. Hacke W, Donnan G, Fieschi C et al. Association of outcome with early stroke treatment: pooled analysis of ATLANTIS, ECASS, and NINDS rt-PA stroke trials. Lancet 2004; 363: 768-74.

5. Lees KR, Bluhmki E, von Kummer R et al. Time to treatment with intravenous alteplase and outcome in stroke: an updated pooled analysis of ECASS, ATLANTIS, NINDS, and EPITHET trials. Lancet 2010: 375: 1695-703.

6. Emberson J, Lees KR, Lyden P et al. Effect of treatment delay, age, and stroke severity on the effects of intravenous thrombolysis with alteplase for acute ischaemic stroke: a meta-analysis of individual patient data from randomised trials. Lancet 2014; 384: 1929-35.

7. Helsenorge.no. Trombolysebehandling av hjerneinfarkt innen 40 minutter. https://helsenorge.no/ Kvalitetsindikatorer/behandling-av-sykdom-ogoverlevelse/trombolysebehandling-etter-40-min (17.11.2016)

8. Evenson KR, Foraker RE, Morris DL et al. A comprehensive review of prehospital and in-hospital delay times in acute stroke care. Int J Stroke 2009. 4: 187-99.

9. Faiz KW, Sundseth A, Thommessen B et al. Prehospital delay in acute stroke and TIA. Emerg Med J 2013: 30: 669-74

10. Fassbender K, Balucani C, Walter S et al. Streamlining of prehospital stroke management: the golden hour. Lancet Neurol 2013; 12: 585-96.

11. Powers WJ, Derdeyn CP. Biller J et al. 2015 American Heart Association/American Stroke Association focused update of the 2013 guidelines for the early management of patients with acute ischemic stroke regarding endovascular treatment: a guideline for healthcare professionals from the American Heart Association/American Stroke Association. Stroke 2015; 46: 3020-35

12. NIHSS. NEL Nevrologi, 2013 http://nevro.legehandboka.no/skjema/ skaringsskjema/nihss-33929.html (9.4.2016).

13. Helsenorge.no. Trombolysebehandling ved blodpropp i hjernen. https://helsenorge.no/kvalitetseksjon/Sider/Kvalitetsindikatorer-rapporter. aspx?kiid=Trombolysebehandling_ved hjerneinfarkt (4.9.2016)

14. Nye kvalitetsindikatorer viser variasjon i tjenestene: Oslo: Helsedirektoratet, 2016. https://helsedirektoratet.no/nyheter/nyekvalitetsindikatorer-viser-variasjon-i-tjenestene (9.4.2016).

15. Faiz KW, Sundseth A, Thommessen B et al. Reasons for low thrombolysis rate in a Norwegian ischemic stroke population. Neurol Sci 2014; 35 : 1977-82

16. Addo J, Ayis S, Leon J et al. Delay in presentation after an acute stroke in a multiethnic population in South london: the South london stroke register. J Am Heart Assoc 2012; 1: e001685.

17. Kim YS, Park SS, Bae HJ et al. Stroke awareness decreases prehospital delay after acute ischemic stroke in Korea. BMC Neurol 2011; 11: 2.

18. Rasura M, Baldereschi M, Di Carlo A et al. Effectiveness of public stroke educational interventions: a review. Eur J Neurol 2014; 21: 11-20.

19. Morgenstern LB, Gonzales NR, Maddox KE et al. A randomized, controlled trial to teach middle school children to recognize stroke and call 911: the kids identifying and defeating stroke project. Stroke 2007; 38: 2972-8

20. Kleindorfer D, Miller R, Sailor-Smith S et al. The challenges of community-based research: the beauty shop stroke education project. Stroke 2008 ; 39: $2331-5$

21. Lecouturier J, Rodgers H, Murtagh MJ et al. Systematic review of mass media interventions designed to improve public recognition of stroke symptoms, emergency response and early treatment. BMC Public Health 2010; 10: 784

22. Faiz KW, Sundseth A. Hvor ble det av tiden? Tidsskr Nor Legeforen 2013; 133: 1057

23. Advani R, Naess H, Kurz M. Mass media intervention in western Norway aimed at improving public recognition of stroke, emergency response, and acute treatment. J Stroke Cerebrovasc Dis 2016; 25: $1467-72$

24. Jauch EC, Saver JL, Adams HP Jr et al. Guidelines for the early management of patients with acute ischemic stroke: a guideline for healthcare professionals from the American Heart Association/Ame rican Stroke Association. Stroke 2013; 44: 870-947.

25. Norges offentlige utredninger. Først og fremst - et helhetlig system for håndtering av akutte sykdommer og skader utenfor sykehus. NOU 2015: 17. https: //regjeringen.no/no/dokumenter/ nou-2015-17/id2465765/ (23.4.2017).

26. Lund CG. Ness E, Rørtveit S et al. For en bedre akuttmedisinsk tjeneste i Norge. Tidsskr Nor Legeforen 2016; 136: 383.

27. Mellor RM, Sheppard JP, Bates E et al. Receptionist $r E$ Cognition and rEferral of Patients with Stroke (RECEPTS): unannounced simulated patient telephone call study in primary care. Br J Gen Pract 2015; 65: e421-7.

28. Jarrell B, Tadros A, Whiteman C et al. National healthline responses to a stroke scenario: implications for early intervention. Stroke 2007; 38: 2376-8.

29. Behandling av hjerneslag: Pasientsikkerhetsprogrammet I trygge hender.

http://pasientsikkerhetsprogrammet.no/no/ I+trygge+hender/Innsatsomr\%C3\%A5der/ Behandling+av+hjerneslag.17.cms (20.9.2016).

Mottatt 7.6. 2016, første revisjon innsendt 30.11. 2016, godkjent 23.3. 2017. Redaktør: Tor Rosness. 